\title{
Choosing The Optimum Frequency Estimator Under System Frequency Deviations In Power Systems
}

\author{
Kenan Gençol ${ }^{1 *}$ \\ 1* Hitit University, Faculty of Engineering, Departmant of Electrical and Electronics Engineering, Çorum, Turkey, (ORCID: 0000-0003-4044-3482), \\ kenangencol@hitit.edu.tr
}

(First received 26 March 2021 and in final form 20 October 2021)

(DOI: $10.31590 /$ ejosat.904157)

ATIF/REFERENCE: Gencol, K. (2021). Choosing The Optimum Frequency Estimator Under System Frequency Deviations In Power Systems. European Journal of Science and Technology, (27), 670-675.

\begin{abstract}
Parameter estimation in particular the frequency estimation of sinusoidal signals contaminated with noise is of great importance due to its broad applications in many fields such as communications, instrumentation, medicine and radar. In current power systems, frequency deviations in the nominal system frequency would cause spurious or so-called ghost frequency components in the spectrum. Those types of frequency components complicate the real-time tracking of harmonics and interharmonics present in the system. In this study, in order to minimize the side effects of system frequency deviations the performances of various frequency estimators are evaluated against varying fundamental frequency and noise conditions and the optimum estimator is chosen.
\end{abstract}

Keywords: Power quality, Harmonics, Fequency estimation, Fequency deviation.

\section{Güç Sistemlerinde Sistem Frekans Kayması Olduğu Durumlarda En Uygun Frekans Kestirici Seçimi}

$\ddot{O} \mathbf{z}$

Parametre tahmini, özellikle gürültü ile kirlenmiş sinüzoidal sinyallerin frekans tahmini, iletişim, enstrümantasyon, tıp ve radar gibi birçok alandaki geniş uygulamaları nedeniyle büyük önem taşımaktadır. Günümüz güç sistemlerinde, nominal sistem frekansındaki frekans sapmaları, spektrumda sahte veya sözde hayalet frekans bileşenlerine neden olmaktadır. Bu tür frekans bileşenleri, sistemde bulunan harmoniklerin ve araharmoniklerin gerçek zamanlı izlenmesini zorlaştırmaktadır. Bu çalışmada, sistem frekans sapmalarının yan etkilerini en aza indirmek için, çeşitli frekans kestiricilerin performansları, değişen temel frekans ve gürültü koşullarına göre değerlendirilmiş ve en uygun kestirici seçilmiştir.

Anahtar Kelimeler: Güç kalitesi, Harmonikler, Frekans tahmini, Frekans kayması.

\footnotetext{
* Corresponding Author: kenangencol@ hitit.edu.tr
} 


\section{Introduction}

Parameter estimation is the task of estimating parameters such as amplitude, frequency and phase of a signal. Estimating the frequency of signals, especially the frequency of a noisecontaminated sinusoid is one of the important topics in the literature as frequency estimation is continuously being applied in many areas such as communication, instrumentation, medicine and radar [1]. The parameter estimation problem was first formulated in the literature by Slepian [2]. The work that Palmer utilized the discrete Fourier transform (DFT) in frequency estimation is one of the initial studies in this field [3]. The parameter estimation problem of single-tone signals from discrete-time observation data has been addressed by Rife and Boorstyn [4]. In this study, the maximum-likelihood estimators for this problem have been derived and their connections with DFT have been explained. Quinn developed two computationally-simple algorithms compared to previous studies based on the interpolation of the Fourier series coefficients at three distinct points [5,6]. Macleod presented a fast algorithm for maximum-likelihood estimation of the parameters of single and multiple tone signals in their study [7]. In addition, an approach based on quadratic interpolation of DFT data was presented in a study by Jacobsen and Kootsookos [8]. Candan proposed an improved algorithm by involving correction factors upon the quadratic interpolation [9]. Frequency estimation have a wide range of applications in power systems including protection, control, monitoring and measurement [10-12].

In real-time power systems, system frequency deviations can rise up to $1 \%$ of its fundamental frequency [13]. This drift in the nominal system frequency causes false (ghost) frequency components that are not present in the true spectrum, making it difficult to monitor and take precautions for harmonics and interharmonics. Harmonics and interharmonics deteriorates power quality by causing distorted supply waveforms, distribution losses and communication interference and hence malfunction protection equipment [14-17]. [15] proposes a saturation detection method based on harmonic distortion for current transformers of $154 \mathrm{kV}$ transmission lines. In [16], a railway system is considered and some proposals are made to solve harmonic related power quality problems encountered in the system. In [17], power quality issues are covered in an induction heating system.

In this study, the performances of various frequency estimators have been assessed against varying system frequency and noise conditions and the optimum estimator is chosen in terms of its accuracy, bias and variance, and computation-time to predict system frequency deviations in the power systems in real-time and minimize their aforementioned side effects.

\section{Material and Method}

In this section, we first give a brief description of the DFT and the effect of the frequency deviation by illustrating with an example. Then, the frequency estimators utilized in this study are given and formulazed. In the last subsection, we give the assessment criteria and the flowchart of the method followed in the work.

\subsection{Discrete Fourier transform (DFT)}

Let a continuous-time $v(t)$ signal be sampled with a sampling rate of $F_{\mathrm{s}}=1 / T_{\mathrm{s}}$, so that $\mathrm{N}$ samples per second be taken. The spectrum of the resulting discrete-time signal $\mathrm{v}(n)=$ $v\left(n T_{\mathrm{s}}\right), n=0,1, \ldots, N-1$ can be obtained by the DFT:

$$
V(k)=\sum_{n=0}^{N-1} v(n) e^{-j 2 \pi k n / N}, \quad k=0,1, \ldots, N-1
$$

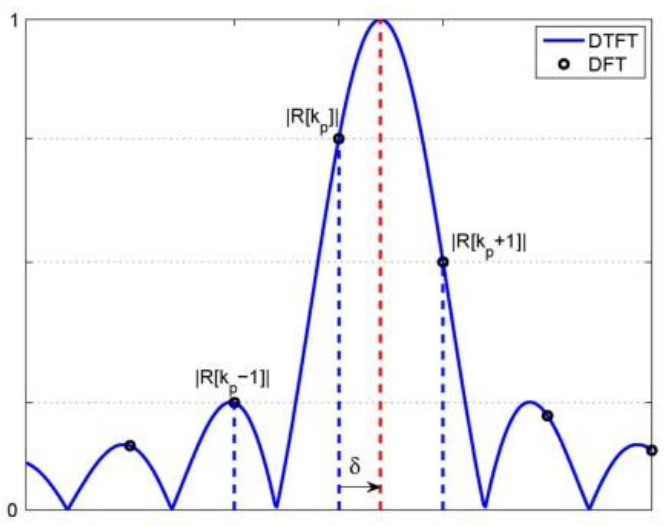

Figure 1. Verification term $\delta$ used to determine the true maximum value in discrete Fourier transform (adapted from [9])

Here $V(k)$ are the spectral components of the discrete-time signal $v(n)$. In order to avoid aliasing, the sampling rate $F_{\mathrm{s}}$ should be chosen as at least twice the highest frequency component contained in the signal.

In the DFT, finite-length (length of $N$ ) samples are taken from the signal. This operation is equivalent to multiplying the signal by a $N$-length rectangular window. Since the ideal rectangular window of finite length in the time domain has infinite length spectral components in the form of $\operatorname{sinc}($.$) function in the$ frequency domain, convolution with the signal in the frequency domain causes a phenomenon known as spectral leakage in which the energy in one frequency band spreads into other bands. To reduce this side effect, different window types that have smaller sidelobes than the rectangular window are utilized.

\subsection{The effect of the frequency deviation}

Let us consider a power signal in the form of $v(t)=$ $\operatorname{Asin}\left(2 \pi f_{0} t\right)$ with a fundamental frequency of $f_{0}=50$. According to the IEC 61000-4-7 standard [18], it is recommended to sample this signal with a sampling rate of $F_{\mathrm{s}}=3.2 \mathrm{kHz}$ and to take the DFT by multiplying it by a rectangular window of length 200 ms. According to this standard, the frequency resolution corresponds to $\Delta f=1 / 200=5 \mathrm{~Hz}$. Here, the fundamental frequency is an integer multiple of the frequency resolution. However, when the system fundamental frequency deviates from its nominal value of $50 \mathrm{~Hz}$, this integer multiplicity relationship does not satisfied anymore and spurious (or ghost) frequency components appear in the spectrum that are not present in the spectrum of the actual signal. Therefore, it is very crucial to estimate the fundamental frequency and adjust the duration of the DFT window accordingly in order to get rid of the pseudofrequency components in the spectrum. 


\subsection{Frequency estimators}

In real life applications, sinusoidal signals appear as noisy. Let

$$
X=A \cos \left(w_{0} * t\right)+n(t)
$$

be a single-tone sinusoidal signal. Here, $A$ is the amplitude of the signal, $w_{0}$ is the frequency of the signal, $n(t) \sim \mathcal{N}\left(0, \sigma^{2}\right)$ is a zero mean $\sigma$ standard deviation additive white Gaussian noise, respectively. Let the DFT of the signal be represented by $X(k)$. The aim here is to estimate the frequency of the tone using three DFT samples, $X_{\mathrm{k}-1}, X_{\mathrm{k}}, X_{\mathrm{k}+1}$. The estimators calculate a verification term $\delta$ to estimate the true $k$ value (the maximum value), i.e, $k_{\text {real }}=k+\delta$ as shown Fig. 1 . For optimality, it should be as accurate as possible, unbiased, and its computation should be fast. Frequency estimators for this purpose are given below:

\subsubsection{Quinn's estimator}

The estimator is obtained from the interpolation of the Fourier series coefficients corresponding to three DFT points:

$$
\begin{gathered}
\alpha_{1}=\operatorname{Re}\left(X_{k-1} / X_{k}\right) \\
\alpha_{2}=\operatorname{Re}\left(X_{k+1} / X_{k}\right) \\
\delta_{1}=\alpha_{1} /\left(1-\alpha_{1}\right) \\
\delta_{2}=-\alpha_{2} /\left(1-\alpha_{2}\right) \\
\text { If } \delta_{1}>0 \& \delta_{2}>0 \delta=\delta_{2} \text { Else } \delta=\delta_{1}
\end{gathered}
$$

\subsubsection{Quinn's second estimator}

This is an improvement upon the Quinn's first estimator. Instead of using comparisons of $\delta_{1}$ and $\delta_{2}$, two factors $\gamma_{1}$ and $\gamma_{2}$ are calculated and $\delta$ is found accordingly.

$$
\begin{gathered}
\alpha_{1}=\operatorname{Re}\left(X_{k-1} / X_{k}\right) \\
\alpha_{2}=\operatorname{Re}\left(X_{k+1} / X_{k}\right) \\
\delta_{1}=\alpha_{1} /\left(1-\alpha_{1}\right) \\
\delta_{2}=\alpha_{2} /\left(1-\alpha_{2}\right) \\
\gamma_{1}=\frac{1}{4} \log \left(3 \alpha_{1}^{4}+6 \alpha_{1}^{2}+1\right)-\frac{\sqrt{6}}{24} \log \frac{\alpha_{1}^{2}+1-\sqrt{2 / 3}}{\alpha_{1}^{2}+1+\sqrt{2 / 3}} \\
\gamma_{2}=\frac{1}{4} \log \left(3 \alpha_{2}^{4}+6 \alpha_{2}^{2}+1\right)-\frac{\sqrt{6}}{24} \log \frac{\alpha_{2}^{2}+1-\sqrt{2 / 3}}{\alpha_{2}^{2}+1+\sqrt{2 / 3}} \\
\delta=\frac{\delta_{1}+\delta_{2}}{2}+\gamma_{2}-\gamma_{1}
\end{gathered}
$$

\subsubsection{Macleod's estimator}

The estimator calculates an offset value by forming a threecoefficient vector with phase verification and utilizes it in the verification term:

$$
R=\operatorname{Re}\left[\left(X_{k-1} \cdot X_{k}^{*}\right)\left(X_{k} \cdot X_{k}^{*}\right)\left(X_{k+1} \cdot X_{k}^{*}\right)\right]
$$

$$
\begin{aligned}
& \gamma=\frac{R(1)-R(3)}{2 R(2)+R(1)+R(3)} \\
& \delta=\left(\left(\sqrt{1+8 \gamma^{2}}\right)-1\right) / 4 \gamma
\end{aligned}
$$

\subsubsection{Candan's estimator}

The estimator is an improvement upon the Jacobsen's quadratic interpolation estimation. Quadratic estimator takes two DFT
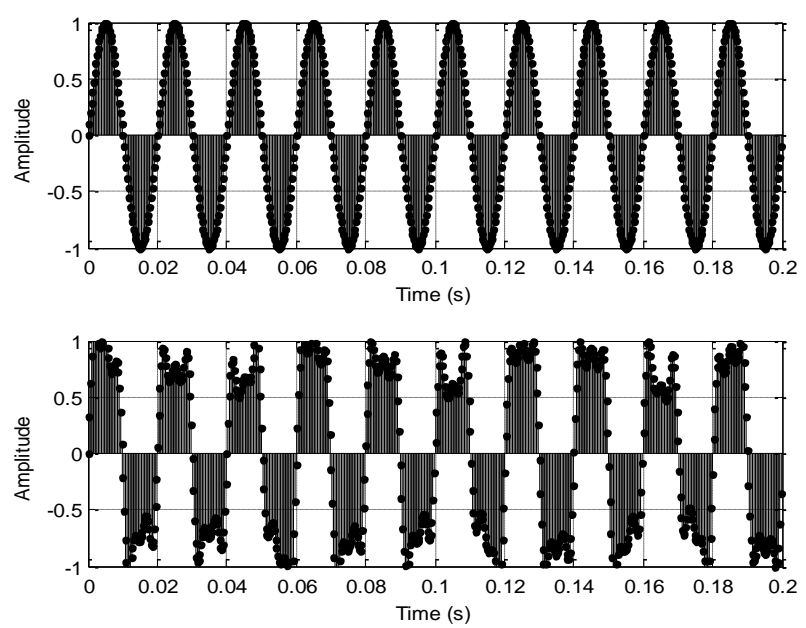

Figure 2. Pure sinusoidal signal and the waveform of the signal in (6) with harmonics and interharmonics in one DFT window period points around the spectral point that has maximum amplitude and calculates the verification term with quadratic interpolation:

$$
\delta=\operatorname{Re}\left[\frac{\left(X_{k-1}-X_{k+1}\right)}{\left(2 X_{k}-X_{k-1}-X_{k+1}\right)}\right]
$$

Candan's estimator calculates two bias correction factors upon the quadratic estimate:

$$
\begin{gathered}
\delta_{C}=\delta \cdot \frac{\tan \pi / N}{\pi / N} \\
\delta_{C}^{\prime}=\frac{\tan ^{-1}\left(\delta_{C} \cdot \pi / N\right)}{\pi / N}
\end{gathered}
$$

\subsection{Assessment criteria and the method}

In order to choose the optimum frequency estimator in the case of system frequency deviations and different noise conditions, we evaluate the aforementioned estimators based on their accuracy, estimator's bias and variance and computation time. The bias and variance of any estimator are given as

$$
\operatorname{Bias}(\omega)=\varepsilon(\omega)-\omega
$$

and

$$
\operatorname{Var}(\omega)=\varepsilon\left[(\omega-\operatorname{Bias}(\omega))^{2}\right]
$$


respectively, where $\mathcal{E}(\boldsymbol{\omega})$ is the expectation operator (true nominal frequency) and $\boldsymbol{\omega}$ is the estimated frequency. The flowchart of the method followed in this work is given Fig. 3.

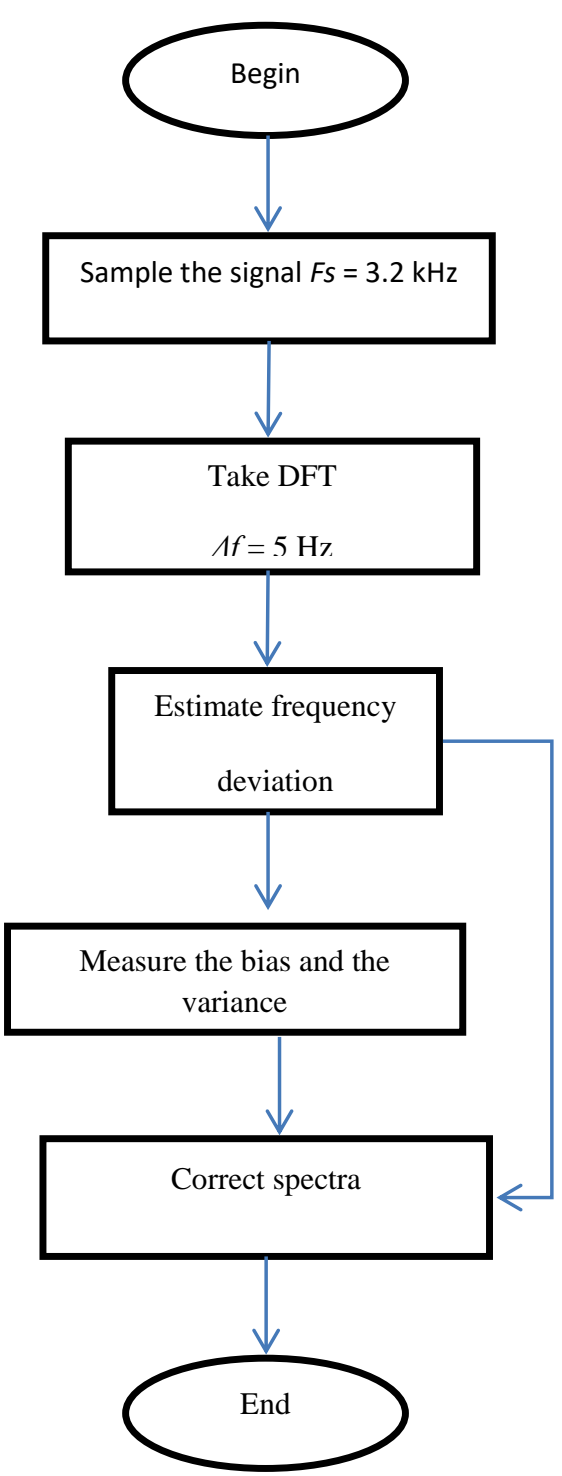

Figure 3. The flowchart of the method

\section{Results and Discussion}

\subsection{The assessment of accuracy and robustness}

A synthesized power signal is used in the assessment of the accuracy and robustness of the estimation methods [19]. The signal is composed of the third and fifth harmonics, together

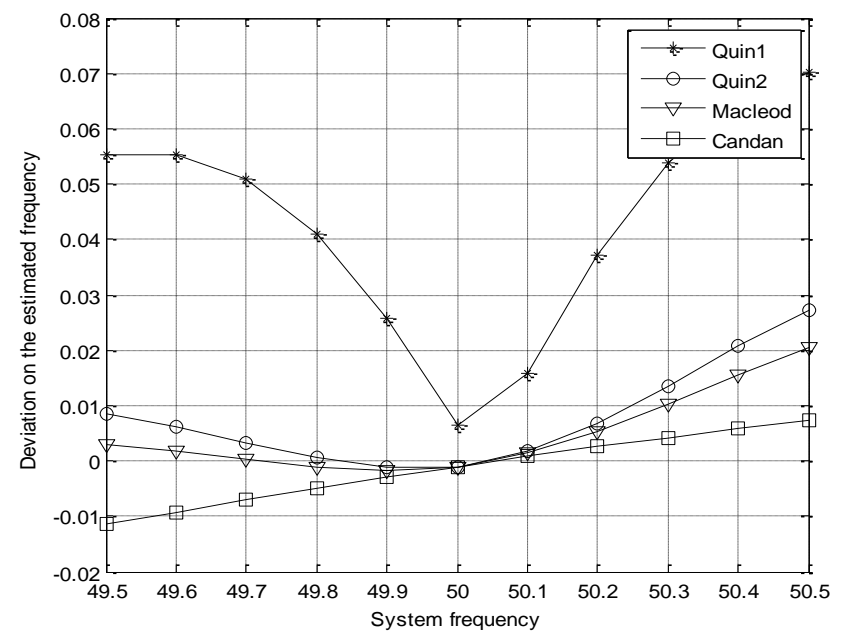

Figure 4. Deviations in the fundamental frequency predicted by estimators when system frequency varies in a noiseless environment

Table 1. Average bias and variances of the estimation methods in a noise-free environment

\begin{tabular}{|l|c|l|}
\hline Estimation method & Bias & Variance \\
\hline Quin1 & 0.0433 & 0.0474 \\
\hline Candan & -0.0014 & 0.0061 \\
\hline Quin2 & 0.0079 & 0.0118 \\
\hline Macleod & 0.0049 & 0.0086 \\
\hline
\end{tabular}

with the signal fundamental component and an interharmonic which is an integer-multiple of the frequency resolution and another interharmonic which is a rational-multiple of the frequency resolution:

$$
\begin{aligned}
& v(t)=\sin \left(2 \pi f_{0} t\right)+0.35 \sin \left(2 \pi 3 f_{0} t\right)+ \\
& 0.2 \sin \left(2 \pi 5 f_{0} t\right)+0.15 \sin (2 \pi 65 t)+0.1 \sin (2 \pi 83 t)
\end{aligned}
$$

Here, the odd harmonics represent the ideal symmetrical waveform, while interharmonics represent contamination in the power line. The waveform and amplitude spectrum of the signal in the time domain is shown in Fig. 2.

Fig. 4 shows the deviations in the fundamental frequency value that the Quin1, Quin2, Candan and Macleod frequency estimators estimate when the system frequency shifts from 50 $\mathrm{Hz}$ to $49.5 \mathrm{~Hz}$ and $50.5 \mathrm{~Hz}(1 \%)$. In such a case, the Quin1 estimator has the highest deviation and hence the lowest performance. In cases where the system frequency decreases below the nominal system frequency of $50 \mathrm{~Hz}$, the best estimator performance is obtained by the Macleod estimator. In cases where the system frequency exceeds $50 \mathrm{~Hz}$ nominal system frequency, the best estimator performance is obtained by the Candan estimator.

Tab. 1 shows the average bias and variance values of the estimation methods in a noiseless environment. When the results are examined, it is observed that the estimator with the lowest bias and variance value is the Candan estimator.

Candan and Macleod estimators that perform best in noiseless environment are examined in varying noise from $20 \mathrm{~dB}$ to $0 \mathrm{~dB}$ SNR. The tests were repeated 10000 times to reflect the varying noise statistics as much as possible for such environment. The average bias and variance results of these estimators are given in 


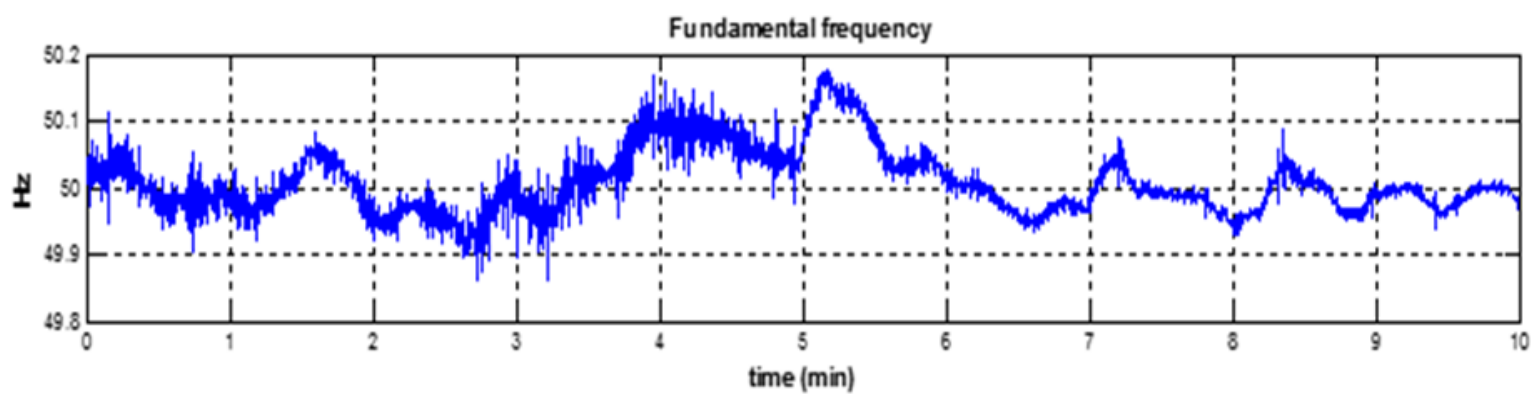

Figure 7. Time-varying frequency characteristic of the EAF field signal

Table 2. Average bias and variance values of Candan And Macleod estimation methods in case of noise

\begin{tabular}{|c|c|c|c|c|c|c|}
\hline Noise & \multicolumn{2}{|c|}{$\mathbf{0 ~ d B}$} & \multicolumn{2}{c|}{$\mathbf{1 0 ~ d B}$} & \multicolumn{2}{c|}{$\mathbf{2 0 ~ d B}$} \\
\hline $\begin{array}{c}\text { Estimation } \\
\text { method }\end{array}$ & Bias & Variance & Bias & Variance & Bias & Variance \\
\hline Candan & $\mathbf{- 0 . 0 0 1 6}$ & 0.1597 & $-\mathbf{0 . 0 0 1 5}$ & 0.0503 & $\mathbf{- 0 . 0 0 1 4}$ & $\mathbf{0 . 0 1 6 0}$ \\
\hline Macleod & 0.0048 & $\mathbf{0 . 1 5 7 1}$ & 0.0048 & $\mathbf{0 . 0 5 0 0}$ & 0.0050 & 0.0167 \\
\hline
\end{tabular}

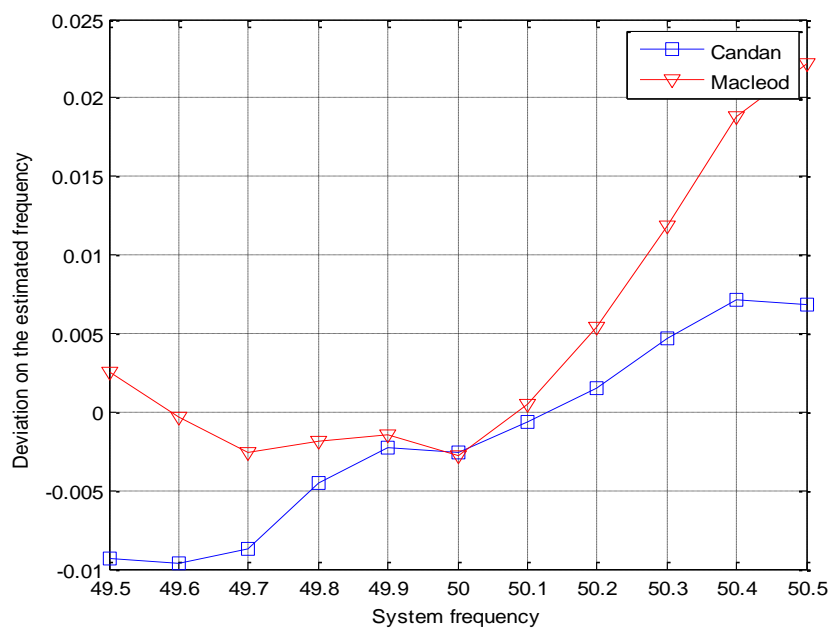

Figure 5. Deviations in the fundamental frequency predicted by the Candan and Macleod estimators when the system frequency varies in case of maximum noise $(0 \mathrm{~dB})$
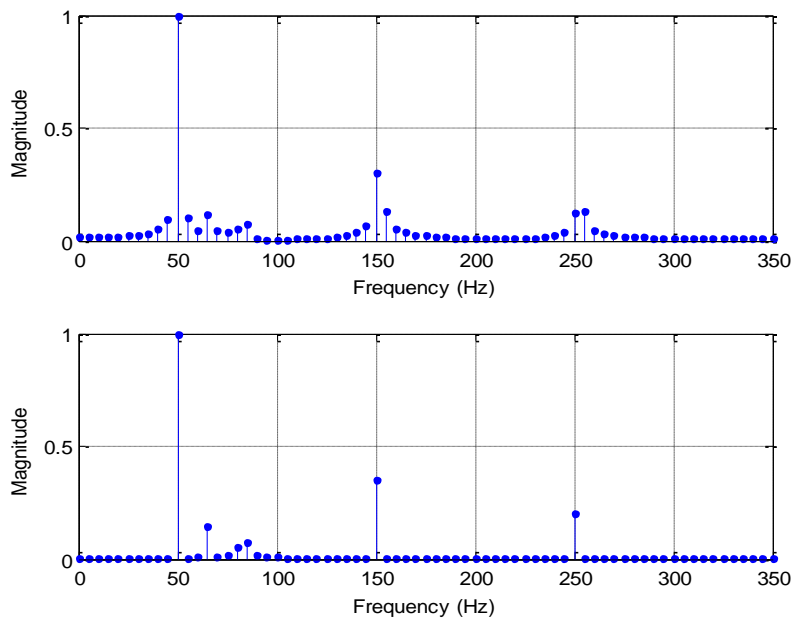

Figure 6. The ghost frequency components seen at the system frequency of $f=50.5 \mathrm{~Hz}$ and the correction of the spectrum after determining the frequency deviation
Tab. 2. If the results in the table are analyzed, although the average variances of both estimators are almost equal, it is observed that the bias values of the Candan estimator are considerably lower than that of the Macleod estimator and this reveals that it is more robust against noise.

The performance of the corresponding estimators in $0 \mathrm{~dB}$ SNR noise condition (maximum noise) is shown in Fig.5. It is notable that still Macleod estimator estimates the frequency more accurately below $50 \mathrm{~Hz}$.

Table 3. Average computation times of the estimation methods in one DFT period

\begin{tabular}{|c|c|}
\hline Estimation Method & $\begin{array}{c}\text { Average computation time in } \\
\text { one DFT period }(\mu \mathrm{s})\end{array}$ \\
\hline Candan & 72.009 \\
\hline Quin1 & 127.835 \\
\hline Quin2 & 68.308 \\
\hline Macleod & 60.098 \\
\hline
\end{tabular}

In the case the system frequency is $50 \mathrm{~Hz}, N=640$ samples are ideally taken with a $200 \mathrm{~ms}$ window with a sampling rate of $F_{s}=$ $3.2 \mathrm{kHz}$. In cases where the system frequency deviates from its nominal value, a new $N$ value should be calculated. Here, the original and corrected spectra with the frequency predicted for the frequency of $f=50.5 \mathrm{~Hz}$, where the variance is maximum (worst case), are given in Fig. 6. As it can be seen, the ghost frequencies formed around the harmonics are removed except for the frequency band wherein the interharmonics are located.

\subsection{The assessment of computational efficiency}

In the assessment of the computational efficiency of the estimation methods, field data which has a time varying fundamental frequency characteristic obtained from electric arc furnace (EAF) plant is employed [13].

Field signal is reconstructed by using a $200 \mathrm{~ms}$ DFT window with a sampling frequency $F s=3.2 \mathrm{KHz}$ as proposed by IEC standard [18]. The fundamental frequency characteristic of the signal is given in Fig. 7. The computation times of the estimators are calculated againt varying frequency in the MATLAB R2018b environment with the Intel Core i5 based 8 GB RAM computer and the average computation times are presented in Tab. 3. As it can be seen from the table, the estimator with the lowest average computation time is the Macleod estimator. Macleod estimator is approximately $12 \mu$ s faster than Candan estimator in computing the system's fundamental frequency per one DFT period, which is a desired property for real-time power systems.

\section{Conclusions}

In this study, in order to minimize the side effects of frequency components called fake or ghost components that occur in the spectrum in the cases of system frequency 
deviations, it is aimed to choose the optimum frequency estimator. It has been found that in noiseless situations Macleod's estimator has the lowest frequency estimation deviation below the nominal system frequency whereas Candan's estimator has the lowest above of the nominal system frequency. In noisy conditions, the estimator with the lowest bias value was found to be the Candan's estimator which reveals its robustness over Macleod's estimator. But, it is also remarkable that Macleod's frequency deviation is lower than Candan's and still performs better than Candan's estimator below the nominal system frequency. When the computation times of the estimators were examined, it is seen that Macleod estimator have the lowest computation time. When both accuracy, robustness and calculation times are assessed, it is concluded that Macleod estimator can be regarded as the most suitable estimator for real-time monitoring.

\section{Acknowledge}

The authors would like to thank Prof. O. Salor-Durna, Department of Electrical and Electronics Engineering, Gazi University, Ankara, Turkey for providing field data used in the experimental work.

\section{References}

[1] Kay, S. M. (1988). Modern spectral estimation: theory and application. Pearson Education India.

[2] Slepian, D. (1954). Estimation of signal parameters in the presence of noise. Transactions of the IRE Professional Group on Information Theory, 3(3), 68-89.

[3] Palmer, L. (1974). Coarse frequency estimation using the discrete Fourier transform (Corresp.). IEEE Transactions on Information Theory, 20(1), 104-109.

[4] Rife, D. C. B. P., \& Boorstyn, R. (1974). Single tone parameter estimation from discrete-time observations. IEEE Transactions on information theory, 20(5), 591-598.

[5] Quinn, B. G. (1994). Estimating frequency by interpolation using Fourier coefficients. IEEE transactions on Signal Processing, 42(5), 1264-1268.

[6] Quinn, B. G. (1997). Estimation of frequency, amplitude, and phase from the DFT of a time series. IEEE transactions on Signal Processing, 45(3), 814-817.

[7] Macleod, M. D. (1998). Fast nearly ML estimation of the parameters of real or complex single tones or resolved multiple tones. IEEE Transactions on Signal processing, 46(1), 141-148.

[8] Jacobsen, E., \& Kootsookos, P. (2007). Fast, accurate frequency estimators [DSP Tips \& Tricks]. IEEE Signal Processing Magazine, 24(3), 123-125.

[9] Candan, Ç. (2013). Analysis and further improvement of fine resolution frequency estimation method from three DFT samples. IEEE Signal Processing Letters, 20(9), 913-916.

[10] López, A., Montaño, J. C., Castilla, M., Gutierrez, J., Borrás, M. D., \& Bravo, J. C. (2008). Power system frequency measurement under nonstationary situations. IEEE Transactions on power delivery, 23(2), 562-567.

[11] Uzunoğlu, C , Çekli, S , Uğur, M . (2011). Adaptive Frequency Estimation of Distorted Power System Signals
Using Modified Extended Kalman Filter . Gazi University Journal of Science, 24 (1) , 85-89.

[12] Markham, P., Zhang, Y., Liu, Y., Stovall, J., Young, M., Gracia, J., \& King, T. (2012, October). Wide-area power system frequency measurement applications. In 2012 Future of Instrumentation International Workshop (FIIW) Proceedings (pp. 1-4). IEEE.

[13] Salor, Ö. (2009). Spectral correction-based method for interharmonics analysis of power signals with fundamental frequency deviation. Electric power systems research, 79(7), 1025-1031.

[14] Kalair, A., Abas, N., Kalair, A. R., Saleem, Z., \& Khan, N. (2017). Review of harmonic analysis, modeling and mitigation techniques. Renewable and Sustainable Energy Reviews, 78, 1152-1187.

[15] Akdağ, O , Yeroğlu, C . (2018). 154 kV İletim Hatlarındaki Akım Transformatörlerinde Simülasyon Modeli ile Harmonik Bozulmaya Dayalı Doygunluk Algılama Yöntemi . Avrupa Bilim ve Teknoloji Dergisi , (14) , 353-363.

[16] Fidan, P , Akdemir, H , Kekezoğlu, B , Adiyıl, İ . (2018). İstanbul'da Bir Rayli Sistem Tesisi'ne Ait Harmonik Analizi ve Çözüm Önerileri . Avrupa Bilim ve Teknoloji Dergisi, (14) , 215-221.

[17] Gökozan, H . (2021). The Effect of an Induction Heating System on Power Quality Parameters . Avrupa Bilim ve Teknoloji Dergisi , (21) , 25-30.

[18] Compatibility, E. General Guide on Harmonics and Interharmonics Measurements and Instrumentation. IEC Standard, 61000-4.

[19] Lin, H. C. (2011). Power harmonics and interharmonics measurement using recursive group-harmonic power minimizing algorithm. IEEE Transactions on Industrial Electronics, 59(2), 1184-1193. 